\title{
Research and Application of Micromotional Exploration in the Middle-Lower Yangtze Metallogenic Belt of China
}

\author{
Xiaoqian Sun, Xinfu Li \\ School of Geophysics and Information Technology, China University of Geosciences, Beijing, China \\ Email: ^xinfuli@cugb.edu.cn
}

How to cite this paper: Sun, X.Q. and Li, X.F. (2021) Research and Application of Micromotional Exploration in the Middle-Lower Yangtze Metallogenic Belt of China. International Journal of Geosciences, 12 , 994-1005.

https://doi.org/10.4236/ijg.2021.1210052

Received: September 16, 2021

Accepted: October 26, 2021

Published: October 29, 2021

Copyright $\odot 2021$ by author(s) and Scientific Research Publishing Inc. This work is licensed under the Creative Commons Attribution International License (CC BY 4.0).

http://creativecommons.org/licenses/by/4.0/

\begin{abstract}
Micromotion is the daily tiny vibration of the earth's surface. Micromotional exploration can use the surface wave information of micro motion to study the shallow structure of underground media. In this study, we collected microtremor data at 68 stations in the Middle-Lower Yangtze Metallogenic Belt (MLYMB) and determined the resonant frequency and obtained the distribution of sedimentary thickness in this area by using $\mathrm{H} / \mathrm{V}$ spectral ratio. According to the results of $\mathrm{H} / \mathrm{V}$, the sedimentary layer in the basin is thick, and the predominant frequency of the basin is $0.05-0.1 \mathrm{~Hz}$. There are no obvious lateral changes in the impedance interface between bedrock and sedimentary layer in this area. The basement of Tongling, Anqing and Luzhou mining areas and their adjacent areas is Kongling-Dongling type basement, which is composed of a set of metamorphic core complex. The predominant frequency is $0.05-0.1 \mathrm{~Hz}$. The sedimentary thickness gradually thinned from $3800 \mathrm{~m}$ in the west to $2100 \mathrm{~m}$ in the East. Moreover, this article used SPAC (spatial autocorrelation) method to obtain the S-wave velocity structure of the mining area near Luzong. The SPAC method reveals that the depth of the interface between the loose sediments and the volcanic rocks is about $600 \mathrm{~m}$ in the study area near the Luzhou mining area in the Middle-Lower Yangtze Metallogenic Belt, and the average depth of the interface between the volcanic rock section and the intrusive complex section is about $1000 \mathrm{~m}$. The thickness of the intrusive rock is more than $2500 \mathrm{~m}$. Tourmaline is developed in the interior of the intrusive rock, which may have better exploration value.
\end{abstract}

\section{Keywords}

H/V Spectral Ratio, Spatial Autocorrelation (SPAC), Middle-Lower Yangtze Metallogenic Belt, Sedimentary Thickness 


\section{Introduction}

The mineralization belt of the Middle-Lower Yangtze area is one of the most important mineral belts in China. It is composed of a series of ore deposits-concentrated areas such as the southeast Hubei, Jiurui, Anqing-Guichi, Tongling, Luzong and Ningwu, etc., which is rich in polymetallic resources, including copper, iron, gold and sulfur [1] [2], having great economic value [3] [4]. Its location is shown in Figure 1. Many geological and geophysical methods have been used to explore this area because of the rich mineral resources, which mainly studies the mineralization and deep mineralization process in the Middle-Lower Yangtze [2] [5] [6]. The occurrence of minerals in the shallow surface of the study area, however, has not been studied by previous geophysical exploration. Although the drilling can directly study the underground structure, it can only obtain the information of individual points. Moreover, the existing drilling data in the study area is less [7], and the cost is too high compared with the H/V spectral ratio and spatial autocorrelation method.

Spectral ratio of horizontal component to vertical component method (H/V) was first introduced by Nogoshi and Igarashi and later generalized by Nakamura [8] [9] [10]. H/V spectral ratios based on microtremor signals can also be used to reliably calculate the resonance frequency and hence thickness of surficial soft sediments [11]-[17]. An empirical equation relating the resonance frequency to sediment thickness was first introduced by Seht and Wohlenberg [18]. Based on the results of $\mathrm{H} / \mathrm{V}$ spectral ratios, Chen et al. depicted the seismic response and

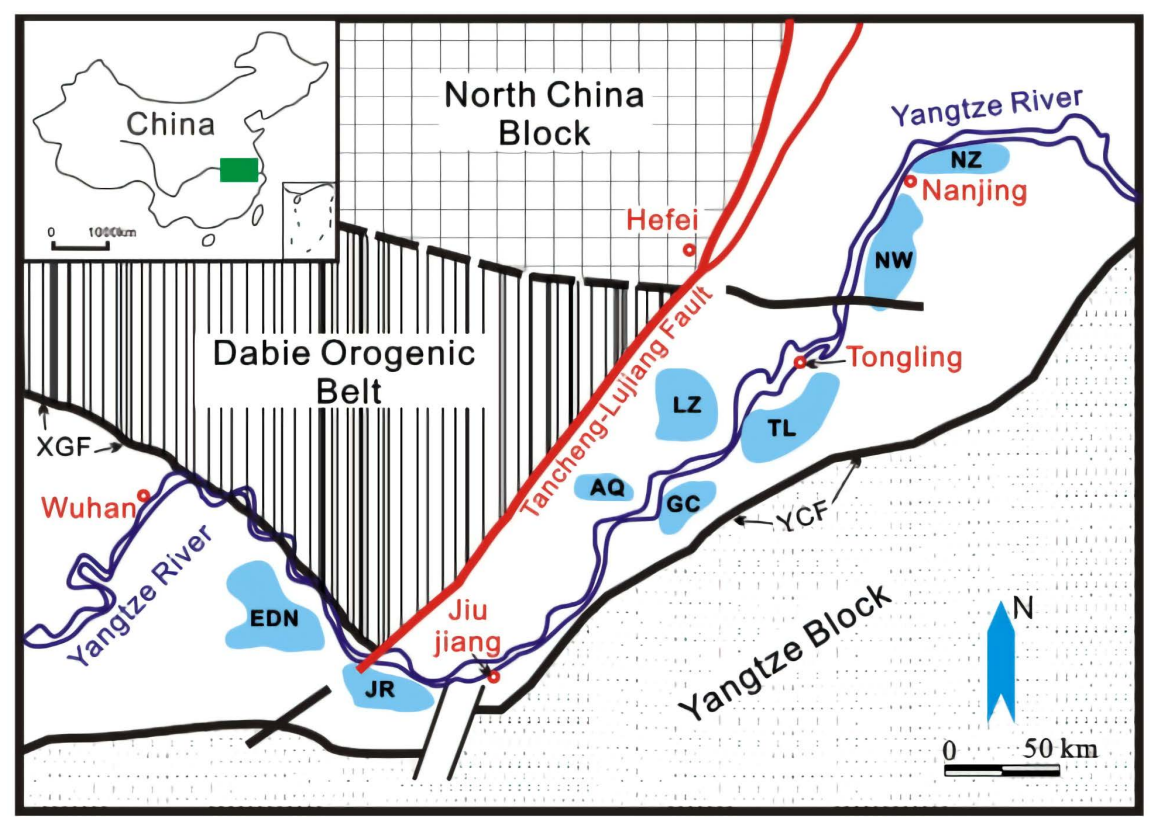

Figure 1. Location and tectonic setting of the study area. The green square in the upper left corner of the illustration shows the geodetic location of the Middle-Lower Yangtze Metallogenic Belt, the red solid line represents the TanLu fault, the blue solid line is the Yangtze River, and the blue irregular figure is the distribution location of the mining area (quoted from Jiang G. M. et al., 2013). 
determined sediment thickness in the Beijing area [19]. Using similar methods, Sukumaran et al. [20] determined the depth profile of the Late Tertiary/Early Quaternary surface in the lower reaches of the Narmada Valley. Using H/V measurements, many researchers have been able to calculate the characteristic site period and thereby estimate sediment thickness [21] [22].

Spatial autocorrelation method (SPAC) was proposed by Akiwhich who laid the foundation of stationary random wave theory [23]. In the 1980s, the SPAC method still has higher requirements for the array layout conditions, and its shape must be a regular polygon tangent to the circle, which greatly limits the application scope of the method. Then, Ling and Okada proposed the ESPAC method [24], which is an improvement of the SPAC method, and its advantage is that the array layout is more flexible. Chavez Garcia et al. proved that spatial averaging can be replaced by using long-time broadband seismic records [25]. Even if the seismograph is not required to be arranged in special geometry, SPAC method can extract better dispersion curve. Spatial autocorrelation method has been widely used to obtain the S-wave velocity structure underground [26] [27] [28] [29]. In this paper, we use SPAC method to obtain the S-wave velocity structure of Luzong mining area.

\section{Geological Background and Data Collection}

The Middle-Lower Yangtze is located at $28^{\circ}$ to $34^{\circ} \mathrm{N}$ and $113^{\circ}$ to $120^{\circ} \mathrm{E}$. After the Triassic Indosinian and Yanshanian movements, the stratigraphic sequence of the Middle-Lower Yangtze consists of three tectonostratigraphic units, namely, the preSinian metamorphic basement, the Sinian Early Triassic submarine sedimentary cover, and the Middle Triassic to Cretaceous continental clastic rocks and volcanic rocks. The special tectonic location, regional dynamic background and deep magmatic process result in the unique volcanic rock distribution and metal mineral accumulation pattern in the area, especially in the Middle-Lower Yangtze River valley metallogenic belt.

The study area of SPAC method is located near Luzong volcanic basin in the Middle-Lower Yangtze metallogenic Belt. The area near Luzong ore concentration area has been in depression environment for a long time from Sinian to Middle Jurassic. The sedimentary strata in this area are mainly sandstone strata of Middle Jurassic, which are composed of iron, sulfur, copper, lead and zinc, alunite, gold, uranium and other deposits.

In order to explore the sedimentary distribution characteristics in the Middle-Lower Yangtze Metallogenic Belt, we collected data from 68 broadband seismic stations deployed by China University of Geosciences (Beijing) from July 2012 to June 2016, including 33 GME-3ESPC broadband seismometers, 25 GME-3ESPCDE broadband seismometers and 10 nanometrics trillium 120 PA. Figure 2 shows the distribution of these stations.

\section{H/V Spectral Ratio}

Firstly, we resample the three-component data to $100 \mathrm{~Hz}$ and intercept the 


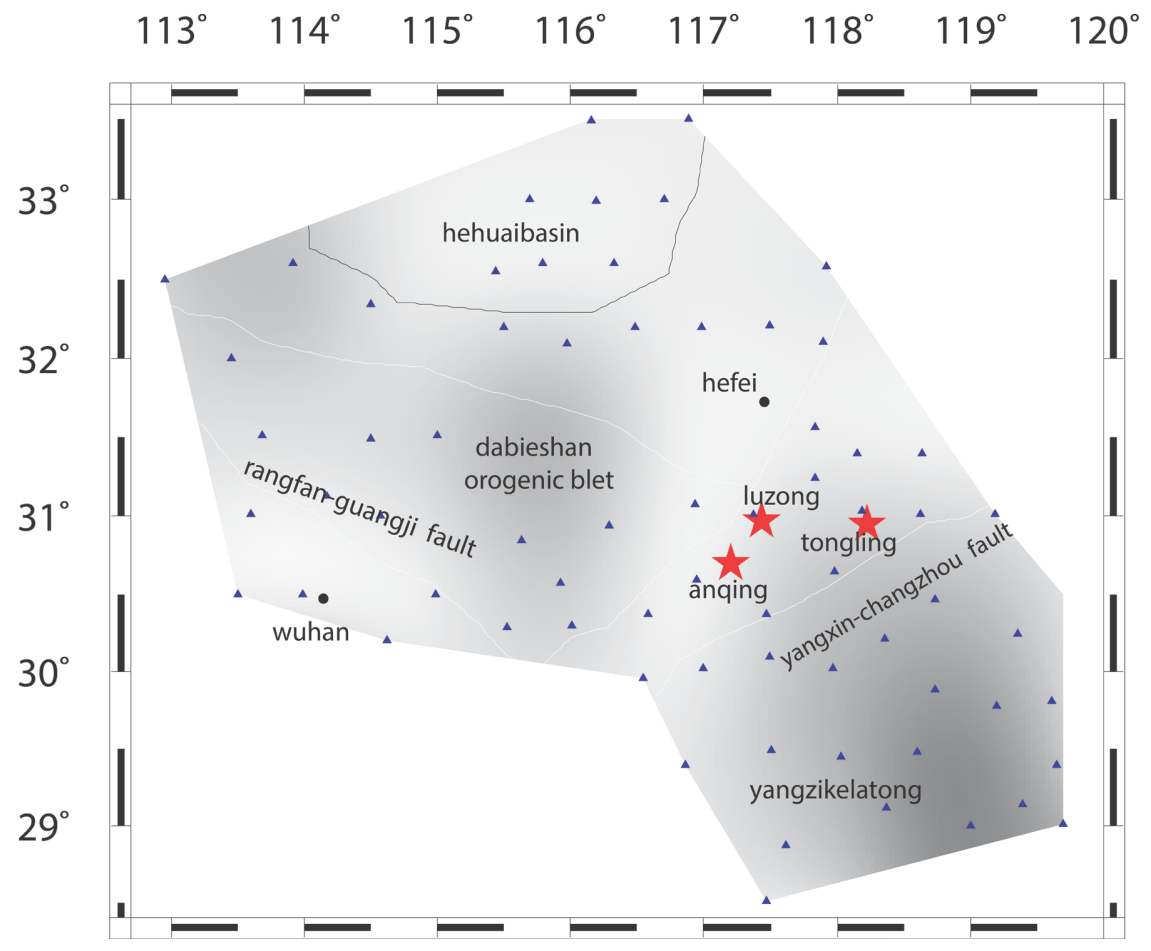

Figure 2. Distribution of stations used in this study. The red pentacles represent Anqing, Tongling and Lubrown mining areas. The blue triangle represents the station, the white solid line represents the faults, the black solid line represents the boundary of the Hehuai basin.

stationary random noise of one hour after eliminating the earthquake events. Then, we calibrate the instrument response, remove mean and remove linear trend. Due to the strong inhomogeneity of the lateral distribution of sedimentary thickness, the data are filtered at $0.05-10 \mathrm{~Hz}$.

After data preprocessing, we calculated the resonance frequencies for all of the microtremor signals at the different sites. The open source Matlab batch program Openhvsr-ProTois used for $\mathrm{H} / \mathrm{V}$ spectral ratio data processing in this study [30]. Figure 3 shows the distribution of H/V curves for the three example stations. Figure 4 shows the resonance frequency distribution in the study area.

\section{Spectral Autocorrelation}

In this paper, we select Luzong mining area as the research area of spatial autocorrelation method. Station distribution is shown in Figure 5. Firstly, the micro motion data of 8 stations are preprocessed, including remove linear trend, instrument response correction, and remove mean. We use $0.1-10 \mathrm{~Hz}$ band-pass filtering for vertical component data to improve the signal-to-noise ratio. Figure 6 shows the noise recording of z-component after the preprocessing. After importing the data into Geopsy software, we combined 8 stations in the study area in pairs to get 21 pairs of stations with different distances. According to the distance and azimuth angle, 21 pairs of stations are grouped. The grouping is based on the fact that each concentric ring should contain as many station pairs as 


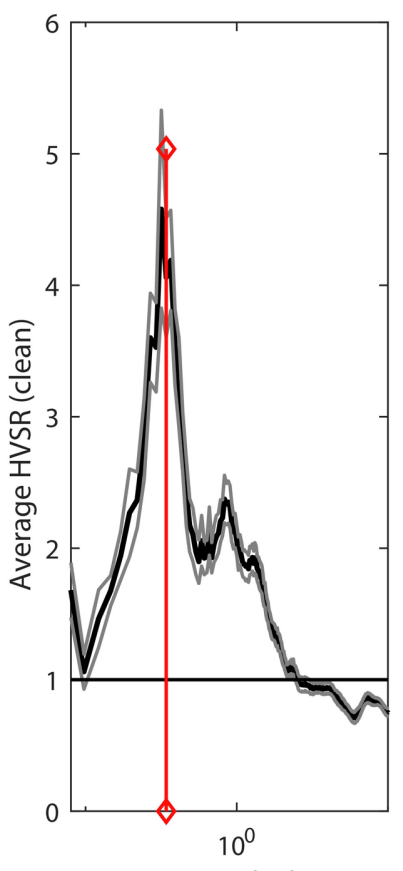

Frequency $(\mathrm{Hz})$

(a)

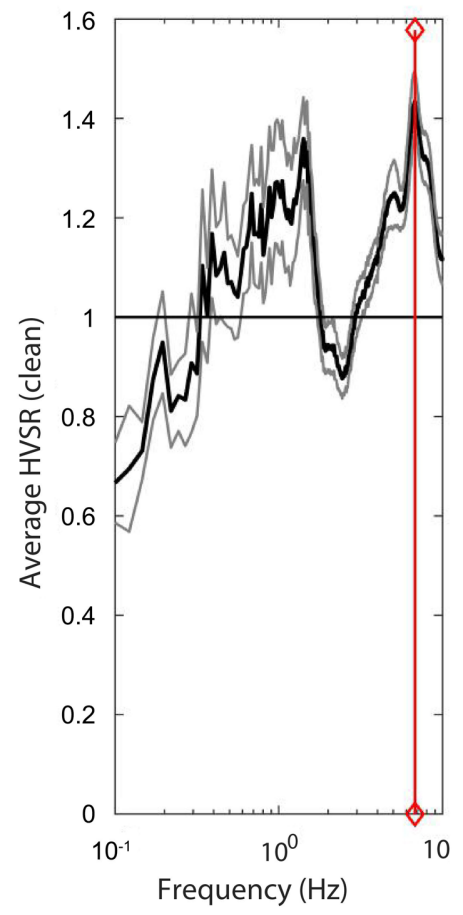

(b)

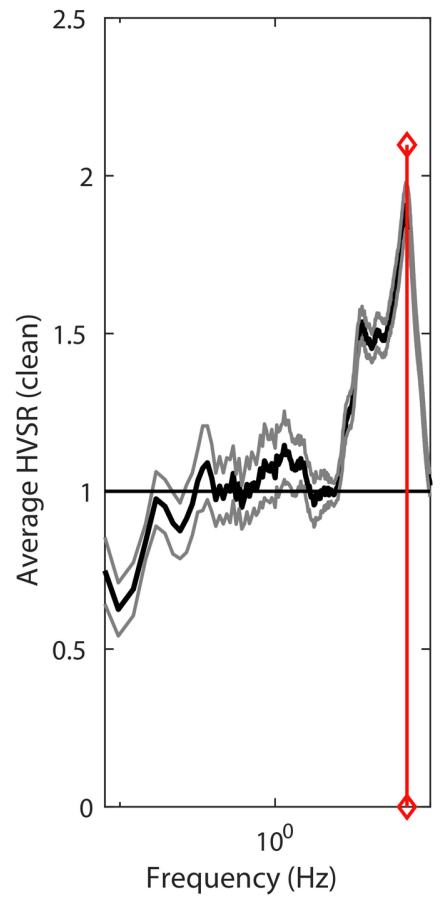

(c)

Figure 3. H/V curves of HF22 (a), HF23 (b) and HF31 (c). The black solid line indicates the average value of $\mathrm{H} / \mathrm{V}$ curve, and the gray solid line is the standard deviation.

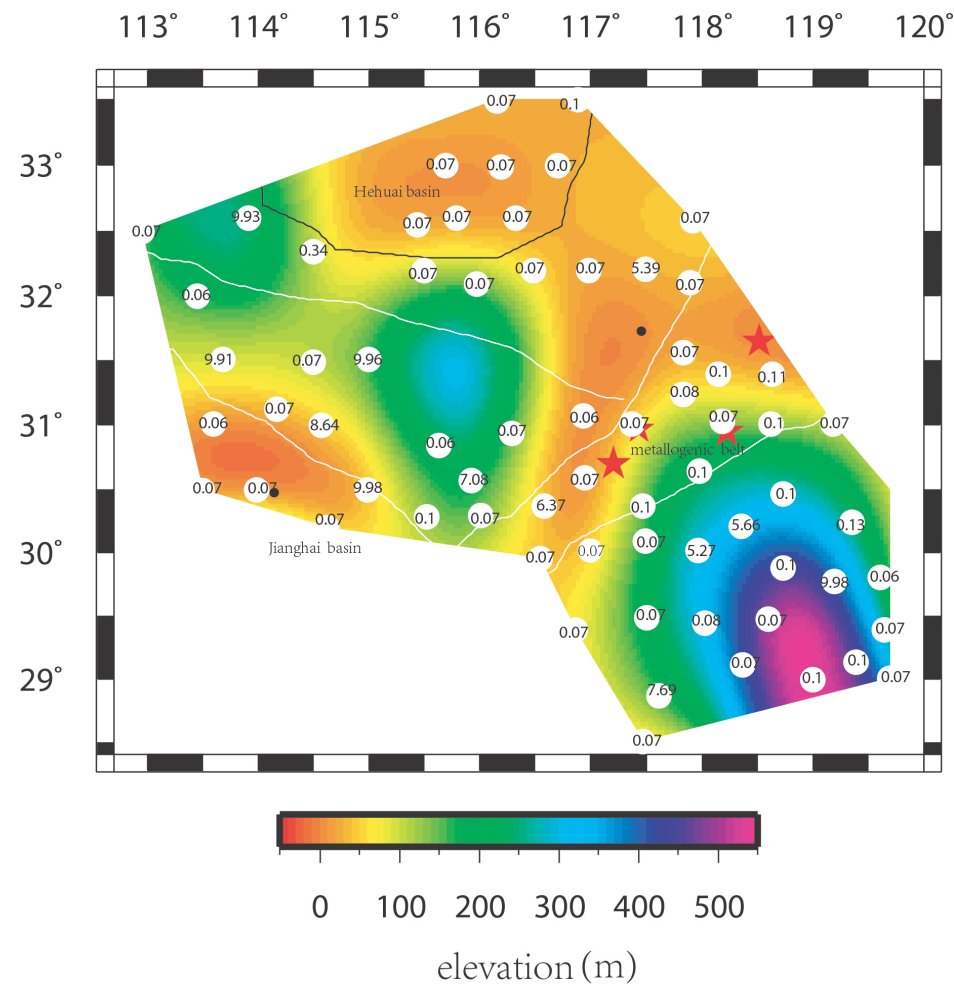

Figure 4. Distribution of predominant frequency in the study area. The white solid line is the fault in the study area, the black solid line is the basin boundary, the red pentacles are the metallogenic belt in the Middle-Lower Yangtze region, the white circle is the predominant frequency beneath each station, the black circle is the city. 


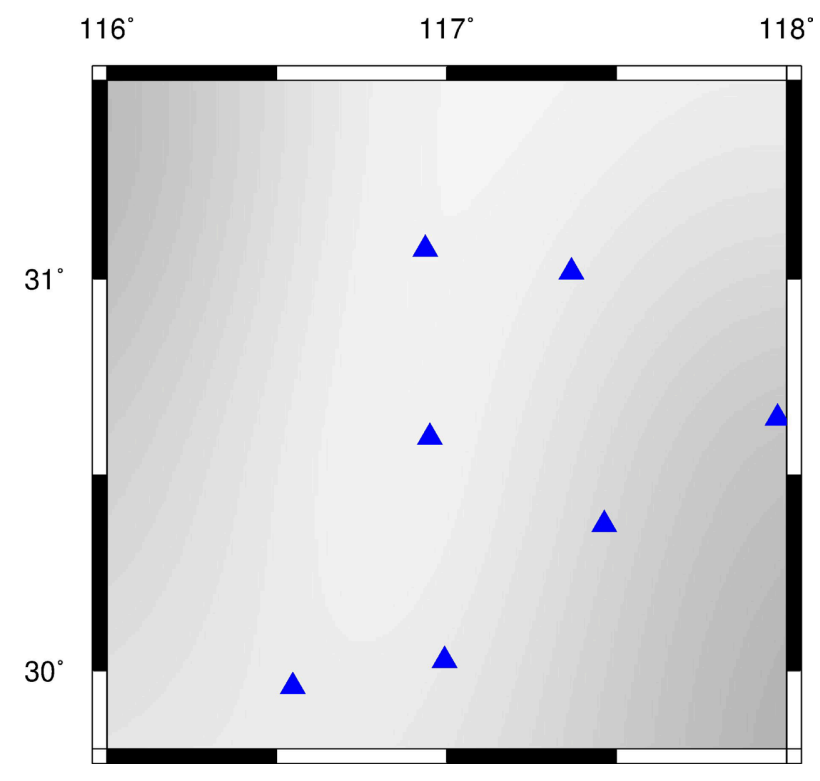

Figure 5. Station distribution of spatial autocorrelation method.

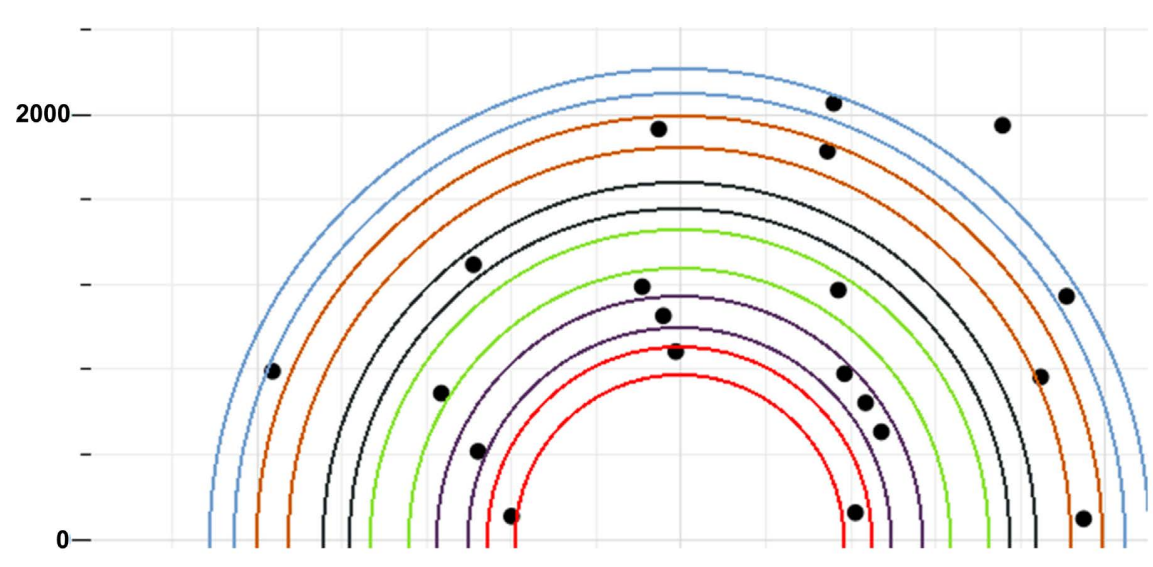

Figure 6. Distribution of station pairs in different radius ranges.

possible, and the azimuth angles of these pairs are as evenly distributed as possible in the concentric circle. The positions of station pairs are shown in Figure 6. Then, the spatial autocorrelation is calculated for the waveform records of each station pair in the same time period. In order to obtain reliable spatial autocorrelation coefficients, it is necessary that spatial autocorrelation curve is averaged in azimuth in the same radius range. Finally, we get 6 spatial autocorrelation function curves, showed in Figure 7.

The dispersion characteristics of surface wave are related to the thickness, density, velocity of P-wave and S-wave. The inversion calculation is effectively the solution of multi extremum problem. Because the dispersion of surface wave is more sensitive to S-wave velocity than P-wave and medium density, only S-wave velocity is inversed in this study. In this paper, the neighborhood algorithm is used to invert S-wave velocity structure. In inversion, the same parameters need to be iterated in many groups, and the one with the smallest residual error is selected as the final result. The S-wave velocity structure obtained by inversion can 


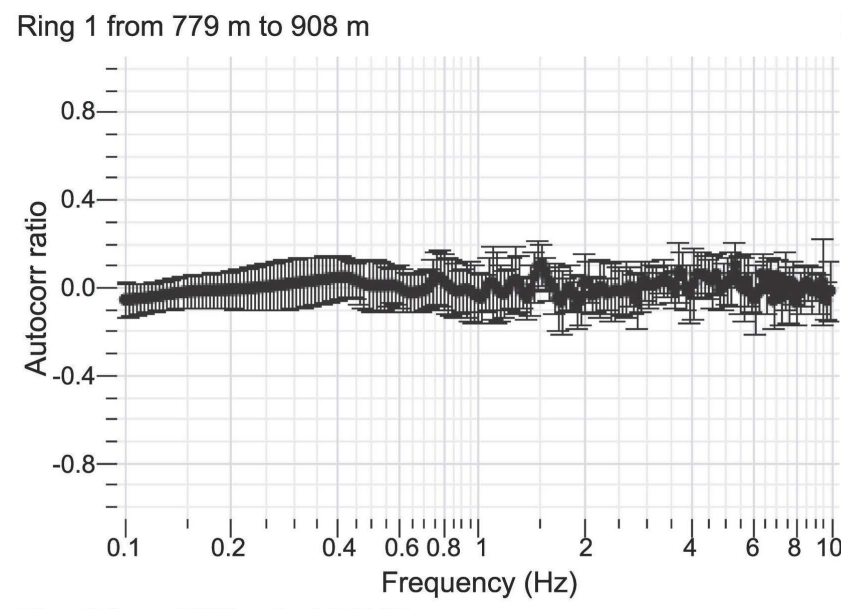

Ring 3 from $1280 \mathrm{~m}$ to $1458.99 \mathrm{~m}$

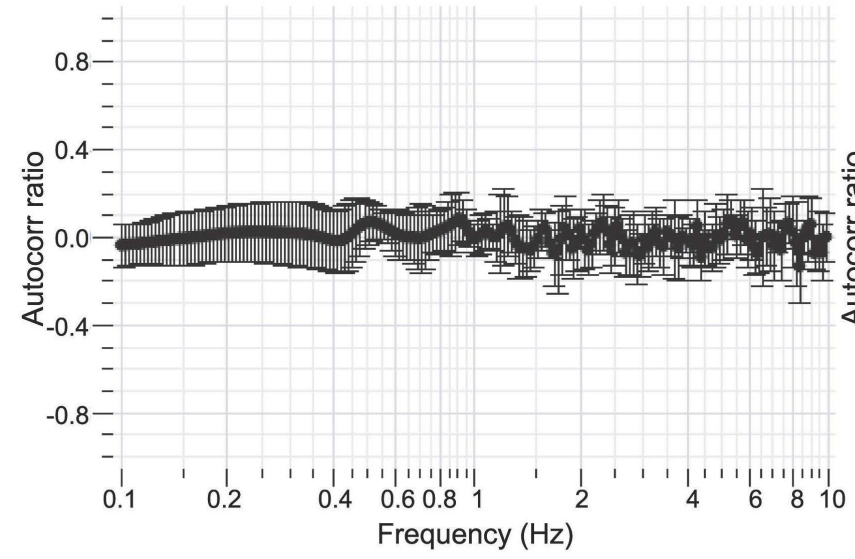

Ring 5 from $1848.57 \mathrm{~m}$ to $2000 \mathrm{~m}$

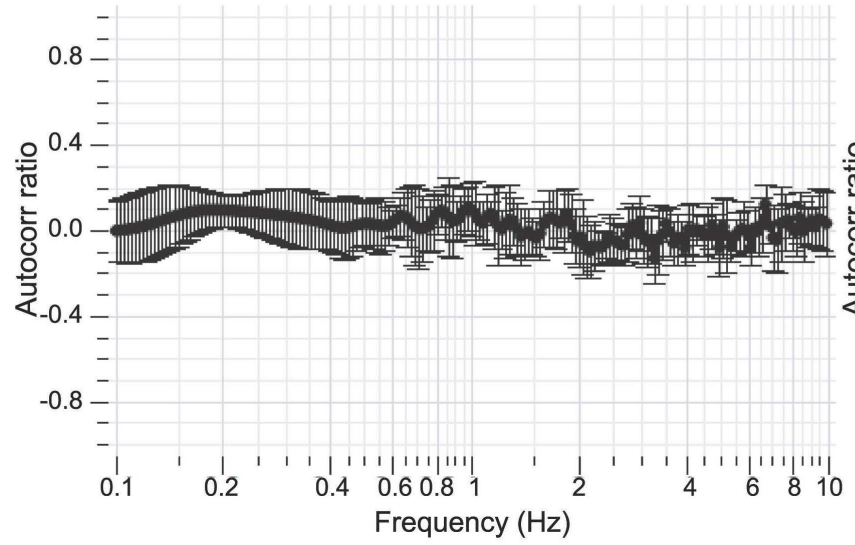

Ring 2 from $1000 \mathrm{~m}$ to $1151.25 \mathrm{~m}$

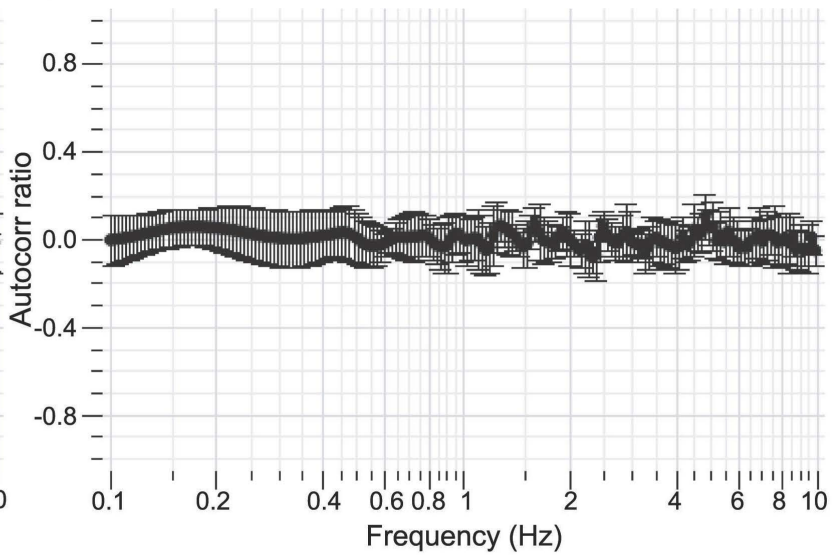

Ring 4 from $1558.51 \mathrm{~m}$ to $1680.57 \mathrm{~m}$

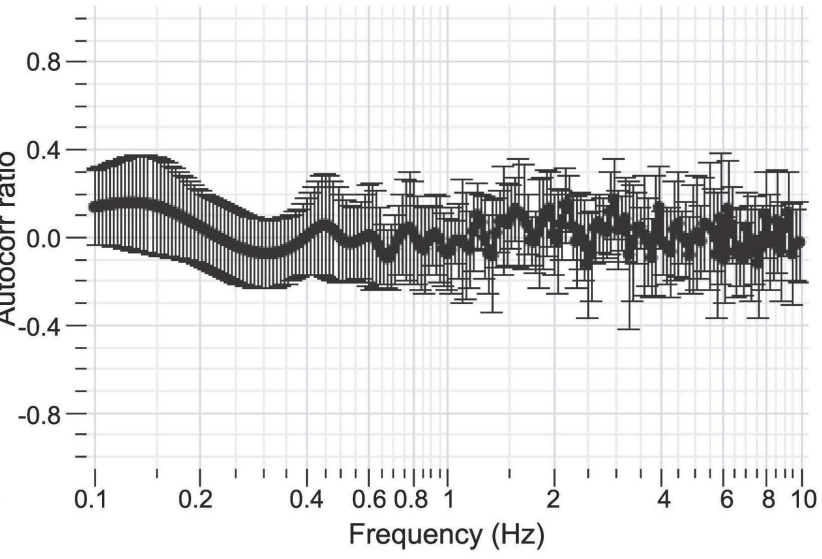

Ring 6 from $2100 \mathrm{~m}$ to $2221 \mathrm{~m}$

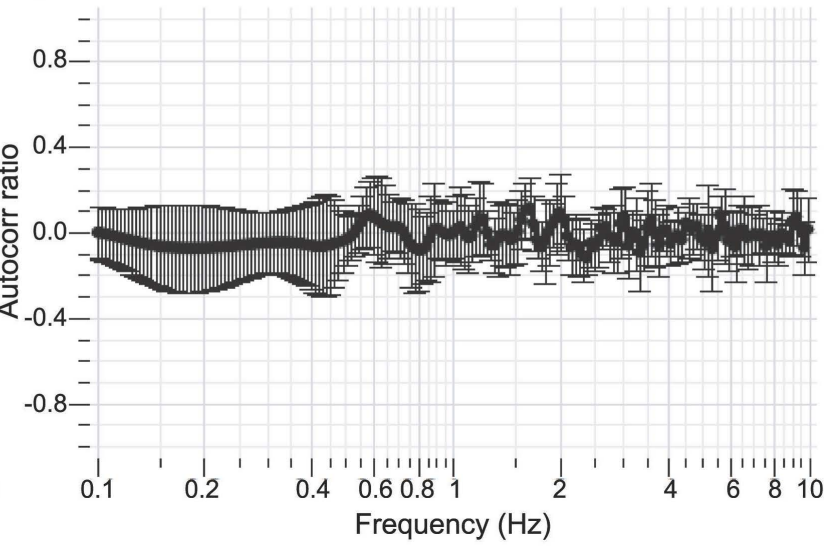

Figure 7. Spatial autocorrelation coefficients in different radius ranges.

be regarded as the average value of S-wave velocity structure in the area covered by 7 stations, as shown in Figure 8(a). Figure 8(b) shows the residual errors in the inversion process.

\section{Results and Discussion}

1) There is an empirical equation that gives the relation between thickness of the sedimentary layer and the resonance frequency, 


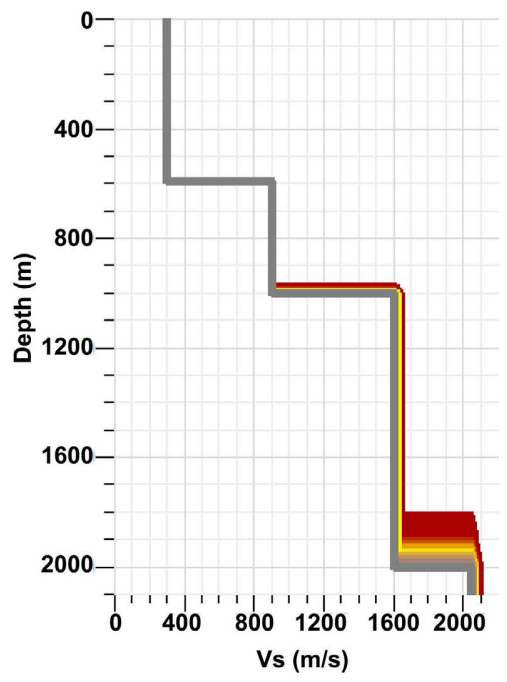

(a)

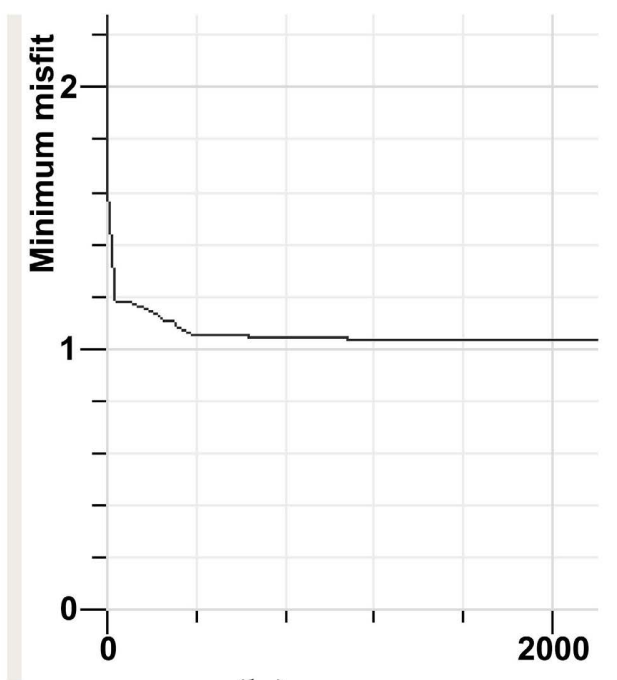

(b)

Figure 8. Average S-wave velocity structure beneath the station.

$$
h=a f^{b}
$$

where $h$ is the thickness of the sedimentary layer, $f$ is the resonance frequency, and $a$ and $b$ are adjustable constants [18]. We can't fine tune the constants $a$ and $b$ of Equation (1) for which we had no enough drill hole data in this local study area. Therefore, we use Equation (2) to calculate the sedimentary thickness of the study area. The sedimentary thickness is shown in Figure 9.

$$
h=96 f^{-1.388}
$$

According to the results of $\mathrm{H} / \mathrm{V}$, the sedimentary layer in the HeHuai basin is thick, and the predominant frequency of the basin is $0.05-0.1 \mathrm{~Hz}$. The Hehuai basin was formed in Cretaceous tertiary, and its lithology mainly includes sandstone, there is no obvious lateral change in the wave impedance interface between bedrock and sedimentary layer in this area. The sedimentary thickness of the margin of Jianghan Basin is more than $3000 \mathrm{~m}$, It shows that the thickness of the central sedimentary layer in Jianghan Basin is relatively deep. The basement of Tongling, Anqing and Luzhou mining areas and their adjacent areas is Kongling-Dongling type basement, which is composed of a set of metamorphic core complex [31]. According to well logging data, the sedimentary above rocks are volcanic rocks and sandstones [7], mainly formed from Sinian to early Cretaceous. The sedimentary cover is volcanic rock [7]. In this area, the predominant frequency is $0.05-0.1 \mathrm{~Hz}$. The sedimentary thickness gradually thinned from $3800 \mathrm{~m}$ in the west to $2100 \mathrm{~m}$ in the East, which is consistent with the change trend of basement [31].

2) The SPAC method reveals that the depth of the interface between the loose sediments and the volcanic rocks in the study area near the Luzhou mining area in the Middle-Lower Yangtze is about $600 \mathrm{~m}$, and the average depth of the interface between the volcanic rock section and the intrusive complex section is about 


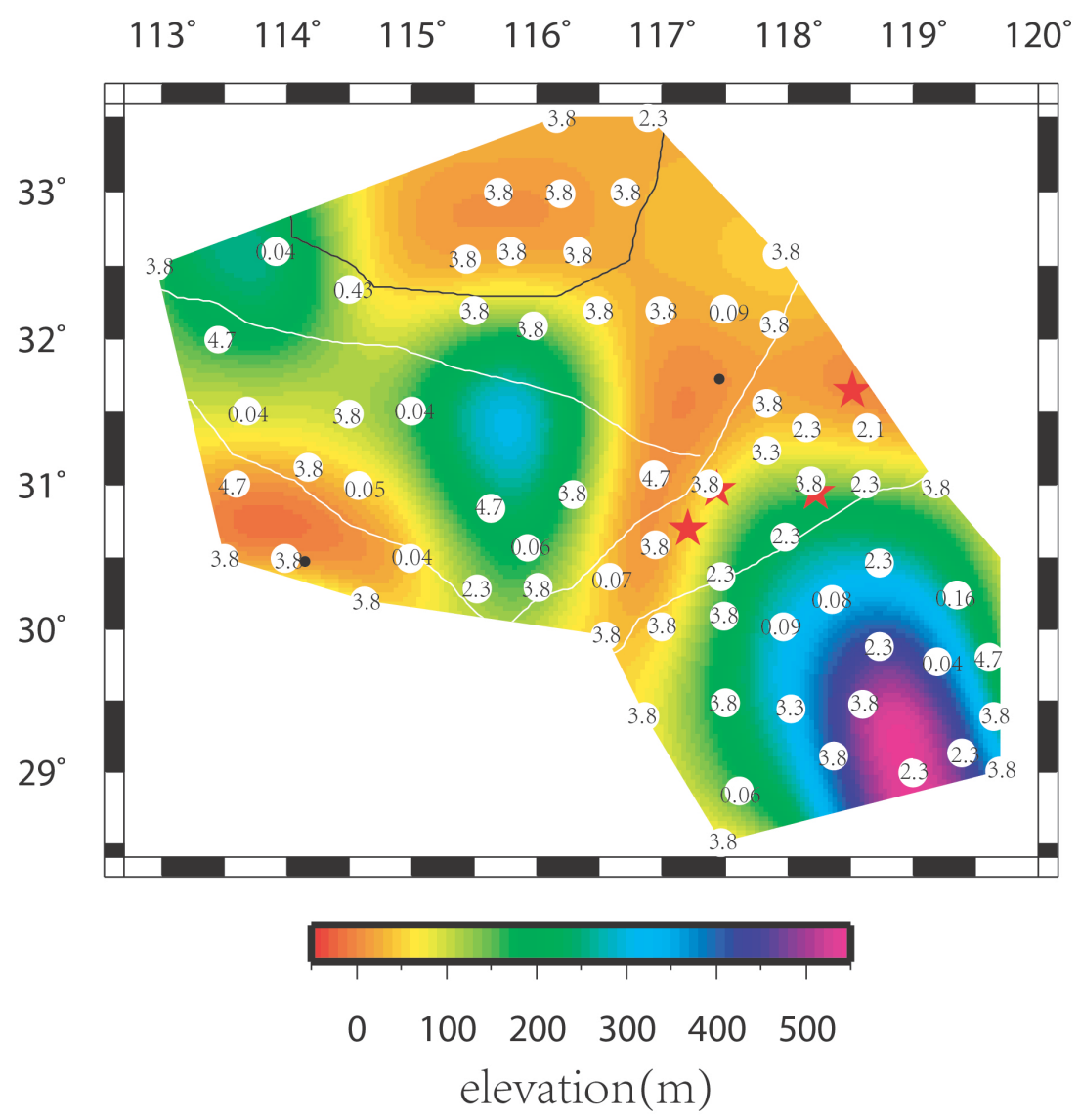

Figure 9. Distribution of sedimentary thickness in the study area. The white solid line is the fault in the study area, the black solid line is the basin boundary, the red five pointed star is the metallogenic belt in the Middle-Lower Yangtze region, the white circle is the sedimentary thickness of each station location, the black circle is the city.

$1000 \mathrm{~m}$. This indicates that the thickness of volcanic rock section in the study area is small. In the formation with depth greater than $1000 \mathrm{~m}$, the thickness of the intrusive rock is more than $2500 \mathrm{~m}$, according to the results of $\mathrm{H} / \mathrm{V}$ spectrum ratio and well logging data. In this formation, tourmaline is developed in the interior of the intrusive rock, which is distributed in black gray clumps and clusters, which may have better exploration value.

3) This study shows that H/V spectral ratio method and spatial autocorrelation play an important role in shallow exploration. In the future, with the maturity of these two technologies, they will have broad application prospects in the study of basin sedimentary mechanism, exploration of geothermal resources, evaluation of landslide hazards and so on.

\section{Conclusions}

In this study, we obtained the distribution of sedimentary thickness in the Middle and Lower Yangtze River by using the H/V spectral ratio method (Spectral ratio of horizontal component to vertical component), obtained the shallow surface S-wave velocity structure of $0-2.2 \mathrm{~km}$ in Luzong mining area by using 
SPAC (spatial autocorrelation) method, predicted and estimated the prospect of mineral exploration, and got the following conclusions:

According to the results of $\mathrm{H} / \mathrm{V}$, spectral ratio method, we can see that after a long period of geological denudation and artificial mining, most areas of the metallogenic area in the middle and lower reaches of the Yangtze River still have thick sedimentary layers, which have good exploration prospects in the future. In Luzong mining area, the thickness of the intrusive rock is more than $2500 \mathrm{~m}$. Tourmaline is developed in the interior of the intrusive rock, which is distributed in black gray clumps and clusters. Carbonate minerals, anhydrite and chalcopyrite are associated with electricity, which may have better exploration potential.

\section{Acknowledgements}

The authors are very grateful to two anonymous reviewers for their thorough reading and constructive comments and suggestions, which greatly aided us in improving the manuscript. This research is financially supported by National Natural Science Foundation of China (Grant Number 41474045).

\section{Conflicts of Interest}

The authors declare no conflicts of interest regarding the publication of this paper.

\section{References}

[1] Mao, J.W., Wang, Y.T., Lehmann, B., et al. (2006) Molybdenite Re-Os and Albite 40Ar/39Ar Dating of Cu-Au-Mo and Magnetite Porphyry Systems in the Yangtze River Valley and Metallogenic Implications. Ore Geology Reviews, 29, 307-324. https://doi.org/10.1016/j.oregeorev.2005.11.001

[2] Jiang, G.M., Zhang, G.B., Lv, Q.T., et al. (2013) 3-D Velocity Model beneath the Middle-Lower Yangtze River and Its Implication to the Deep Geodynamics. Tectonophysics, 606, 36-47. https://doi.org/10.1016/j.tecto.2013.03.026

[3] Liang, W., Gong, W., Wei, S., et al. (2015) The Worth and the Significance of Port in Economic Integration Development Model: A Case Study on Yangtze River Economic Belt of China. Open Journal of Social Sciences, 3, 44-55.

https://doi.org/10.4236/jss.2015.312005

[4] Yu, X.G., Wang, L., Yang, Q.K., et al. (2015) Background of the Yangtze River Economic Belt Development Strategy and Geography Interpretation of Its Innovative Development. Progress in Geography, 34, 1368-1376.

[5] Li, S.G. (2001) Deep Tectonic Setting of Mesozoic Magmatic Rocks and Cu Fe Metallogenic Belt in the Middle and Lower Reaches of the Yangtze River. Geology of Anhui Province, No. 2, 118-122.

[6] Xu, Y., Lv, Q.T., Zhang, W.B., et al. (2015) 3D S-Wave Velocity Structure of the Middle and Lower Yangtze Metallogenic Belt and Its Constraints on Deep Processes. Acta Geophysica Sinica, 58, 4373-4387.

[7] Xue, H.M., Wu, M.A. and Ma, F. (2014) Deep Rock Association and Alteration Mineralization of Luzong Volcanic Basin Revealed by Lzsd of Luzong Scientific Drilling. Chinese Geophysical Society. 
[8] Nogoshi, M. and Igarashi, T. (1971) On the Amplitude Characteristics of Microtremor (Part 2) Zisin (Journal of the Seismological Society of Japan. 2nd ser.). https://doi.org/10.4294/zisin1948.24.1 26

[9] Nakamura, Y. (1989) A Method for Dynamic Characteristics Estimation of the Subsurface Using Microtremor on the Ground Surface. Quarterly Report of RTRI, 30, 25-33.

[10] Nakamura, Y. (2000) Clear Identification of Fundamental Idea of Nakamura's Technique and Its Applications. 12th World Conference on Earthquake Engineering, Auckland, 30 January-4 February 2000, 8.

[11] Field, E.H. and Jacob, K. (1993) The Theoretical Response of Sedimentary Layers to Ambient Seismic Noise. Geophysical Research Letters, 20, 2925-2928. https://doi.org/10.1029/93GL03054

[12] Lermo, J. and Arcia, C.G. (1994) Are Microtremors Useful in Site Response Evaluation. Bulletin of the Seismological Society of America, 84, 1350-1364.

[13] Mucciarelli, M. (1998) Reliability and Applicability of Nakamura's Technique Using Micro Tremors: An Experimental Approach. Journal of Earthquake Engineering, 2, 625-638. https://doi.org/10.1080/13632469809350337

[14] Parolai, S., Bormann, P. and Milkereit, C. (2001) Assessment of the Natural Frequency of the Sedimentary Cover in the Cologne Area (Germany) Using Noise Measurements. Journal of Earthquake Engineering, 5, 541-564.

https://doi.org/10.1080/13632460109350405

[15] Haghshenas, E., Bard, P.Y., Theodulidis, N., et al. (2008) Empirical Evaluation of Microtremor H/V Spectral Ratio. Bulletin of Earthquake Engineering, 6, 75-108.

https://doi.org/10.1007/s10518-007-9058-x

[16] Rincon, O., Shakoor, A. and Ocampo, M. (2016) Investigating the Reliability of H/V Spectral Ratio and Image Entropy for Quantifying the Degree of Disintegration of Weak Rocks. Engineering Geology, 207, 115-128. https://doi.org/10.1016/j.enggeo.2016.04.020

[17] Bignardi, S. (2017) The Uncertainty of Estimating the Thickness of Soft Sediment with the HVSR Method: A Computational Point of View on Weak Lateral Variations. Journal of Applied Geophysics, 145, 28-38. https://doi.org/10.1016/j.jappgeo.2017.07.017

[18] Seht, I.V. and Wohlenberg, J. (1999) Microtremor Measurements Used to Map Thickness of Soft Sediment. Bulletin of the Seismological Society of America, 89, 250-259. https://doi.org/10.1785/BSSA0890010250

[19] Chen, Q.F., Liu, L.B., Wang, W.J., et al. (2008) Site Effects on Earthquake Ground Motion Based on Microtremor Measurements for Metropolitan Beijing. Chinese Science Bulletin, 52, 2229-2235.

[20] Sukumaran, P., Parvez, I.A., Sant, D.A., et al. (2011) Profiling of Late Tertiary Early Quaternary Surface in the Lower Reaches of Narmada Valley Using Microtremors. Journal of Asian Earth Sciences, 41, 325-334. https://doi.org/10.1016/j.jseaes.2011.02.011

[21] Guo, Z., Aydin, A. and Kuszmaul, J.S. (2014) Microtremor Recordings in Northern Mississippi. Engineering Geology, 179, 146-157. https://doi.org/10.1016/j.enggeo.2014.07.001

[22] Yilar, E., Baise, L.G. and Ebel, J.E. (2017) Using H/V Measurements to Determine Depth to Bedrock and Vs30 in Boston, Massachusetts. Engineering Geology, 217, 12-22. https://doi.org/10.1016/j.enggeo.2016.12.002 
[23] Aki, K. (1957) Space and Time Spectra of Stationary Stochastic Waves, with Special Reference to Microtremors. Bulletin of the Earthquake Research Institute, 35, 415-456.

[24] Henstridge, J.D. (1979) A Signal Processing Method for Circular Arrays. Geophysics, 44, 179-184. https://doi.org/10.1190/1.1440959

[25] Ling, S. and Okada, H. (1993) An Extended Use of the Spatial Autocorrelation Method for the Estimation of Geological Structure Using Microtremors. Proceedings of the 89 th SEGJ Conference, Japanese, 44-48. (In Japanese)

[26] Chavez-Garcia, F.J., Rodriguez, M. and Stephenson, W.R. (2005) An Alternative Approach to the Analysis of Microtremors-Exploiting Stationarity of Noise. Bulletin of the Seismological Society of America, 95, 277-293.

https://doi.org/10.1785/0120030179

[27] Kudo, K. (2002) Site-Specific Issues for Strong Ground Motions during the Kocaeli, Turkey, Earthquake of 17 August 1999, as Inferred from Array Observations of Microtremors and Aftershocks. Bulletin of the Seismological Society of America, 92, 448-465. https://doi.org/10.1785/0120000812

[28] Apostolidis, P., Raptakis, D., Roumelioti, Z., et al. (2004) Determination of s-Wave Velocity Structure Using Microtremors and Spac Method Applied in Thessaloniki (Greece). Soil Dynamics \& Earthquake Engineering, 24, 49-67. https://doi.org/10.1016/j.soildyn.2003.09.001

[29] Asten, M.W., Askan, A., Ekincioglu, E., et al. (2014) Site Characterization in North-Western Turkey Based on SPAC and HVSR Analysis of Microtremor Noise. Exploration Geophysics, 45, 74-85. https://doi.org/10.1071/EG12026

[30] Bignardi, S., Mantovani, A. and Abu Zeid, N. (2016) OpenHVSR: Imaging the Subsurface 2D/3D Elastic Properties through Multiple HVSR Modeling and Inversion. Computers \& Geosciences, 93, 103-113. https://doi.org/10.1016/j.cageo.2016.05.009

[31] Liu, G., Dong, S.W., Ma, L.C., et al. (2016) Basement and Mineralization in the Middle and Lower Reaches of the Yangtze River. Acta Geologica Sinica, 90, 2258-2275. 